\title{
Are American Presidents Becoming Less Rhetorically Complex? Evaluating the Integrative Complexity of Joe Biden and Donald Trump in Historical Context
}

\author{
Lucian Gideon Conway, III \\ Alivia Zubrod \\ University of Montana
}

Corresponding Author:

Lucian Gideon Conway, III,

Professor, Psychology Department

University of Montana

Missoula, MT 59812

Luke.conway@umontana.edu

This working paper has not yet been peer-reviewed. 


\begin{abstract}
Are American political leaders becoming simpler in their rhetoric? To evaluate, in the present study we place the two most recent U.S. presidents' integrative complexity against a historical context for three different types of comparable materials: Presidential Debates, Inaugural Addresses, and State of the Union (SOTU) speeches. Results overwhelmingly suggest that both Joe Biden and Donald Trump are historically simple when compared to the typical president, and that is true both across parties and within their own political party. Further, segmented regression analyses suggest that part of the reason for Biden's and Trump's low complexity is the continuation of an ongoing historical decline in complexity among Presidents that began in 1960. However, each president uniquely defies this trend on one material type: Biden is a historical outlier for his low-complexity debates, and Trump is a historical outlier for his lowcomplexity inauguration speech. Taken as a whole, these data suggest that although American presidents have been declining in complexity, both Biden and Trump are nonetheless uniquely low in complexity in some ways - possibly for reasons that are different for each president.
\end{abstract}

Keywords: Integrative complexity, U.S. presidents, Donald Trump, Joe Biden 


\section{Are American Presidents Becoming Less Rhetorically Complex? Evaluating the Integrative Complexity of Joe Biden and Donald Trump in Historical Context}

The last five years have proven to be especially divisive in American politics. At the end of 2016, Time magazine designated former president Donald Trump as "President of the Divided States of America." This foreshadowed the years to follow. Even early in Trump's presidency, polling found that $77 \%$ of American adults agreed with the statement, "Americans are greatly divided when it comes to the most important values" (Tarrance, 2017). Since then, Donald Trump has had two historic impeachment trials led by Democratic leaders (Roche, 2021). Amid these trials, clear disdain for Trump grew, as evident in House Speaker Nancy Pelosi's act of tearing up Trump's State of the Union Address (Mansoor, 2020). While the 2020 election brought hope for more unity in some quarters, both Biden and Trump supporters (89\% and 90\%, respectively) felt that if the other won, it would result in irreparable damage to America (Dimock \& Wike, 2020). Even after Joe Biden won, political division remained, from rioting in the Capitol to Biden's presidential approval rating showing greater partisan divide than his predecessors (Jones, 2021). The culmination of the last five years and the 2020 election has been historical on numerous fronts, but perhaps the LA Times headline sums it up best, “Americans broke a 120-year-old turnout record - and are more divided than ever" (Lauter \& Hook, 2020).

This division has been accompanied by very divisive and often simplifying rhetoric. Indeed, Donald Trump - one of the two presidents at the focal point of this scientific paper - was in popular parlance considered an architect of simple dialogue. During his political campaign, Trump often made dogmatically uncivil (Conway et al., 2017; Frimer \& Skitka, 2018), prejudicial, and offensive comments targeting various individuals and 
groups, including immigrants (Crandall et al., 2018), women (McCammon, 2016), and disabled people (Carmon, 2016). While it is conceptually possible to use belligerent, racist, and sexist rhetoric in a complex fashion, this kind of rhetoric likely nonetheless contributed to a general perception that Trump is rhetorically simple. As writer Gwenda Blair (2016) wrote on the popular British news outlet The Guardian: “Trump's speech is hardly bristling with complexity. Rather, his vocabulary is extremely simple, almost to the point of being childish..." Similarly, a news article from Time (French, 2019) chastised Trump's "single-minded self-focus...the stories paint a picture of a president who is both petty and small, so very small." Sometimes one does not even have to get past the headline to get the point, as seen in article titles like "The Simple Mind of Donald Trump" (Daily Kos, 2019) and the even less subtle "Donald Trump is a SimpleMinded Bully Who Knows Only One Tactic” (Atkins, 2018). Indeed, his simple rhetoric was even tied in popular media to his appeal, as stated in an LA Times op-ed (Akst, 2019): “Trump's simple-minded emphasis on a wall and even his callous indifference to immigrant children have said loudly to the swing voters who will decide the election that, on this issue too, he has gotten the message." Thus, Donald Trump seems popularly considered almost iconically simple-minded (see Blair, 2016; Conway et al., 2017; Conway et al., 2020; Lee, 2017).

Trump's presidential successor, Joe Biden, was arguably presented in a more nuanced fashion in the lead-up to the 2020 election. On the one hand, attention was drawn towards his political experience, and a media picture was painted of a leader with a steady hand. For instance, after Obama's official endorsement of Biden, headlines commented on the faith Obama placed in Biden, "Obama endorses Biden for president, says he's the right person to 'guide us through one of our darkest times'” (Smith et al., 
2020). On the other hand, some suggested that Biden's central political messaging was nonetheless rather simple; as a New York Times headline read, "Biden always had a simple message. He rode it to the nomination" (Martin, 2020). Further, there were questions raised prior to his election about whether or not his cognitive abilities were in decline, such as the Washington Post headline that read "It's fair to speculate whether Biden is mentally fit to be president" (Thiessen, 2020).

However interesting these speculations are, it nonetheless is still wanting for scientific evidence. In reality, did Donald Trump or Joe Biden (or both) use especially simple rhetoric? And if so, was this simplicity part of a larger linear decline in American politics, or was it unique to the two presidents? We aim to answer precisely these two questions in the present research. Although many different ways to evaluate the complexity of language exist (e.g., Abe, 2011, 2012; Hermann, 1980; Jordan et al., 2019), we focus here on a widely validated measurement of the complexity of rhetoric: Integrative Complexity.

\section{Integrative Complexity}

Designed in its current instantiation by Peter Suedfeld's lab (e.g., Suedfeld et al., 1977), integrative complexity is the measurement of the degree that spoken or written materials have differentiation (the recognition of different distinct dimensions) and integration (the subsequent recognition of interrelations among differentiated dimensions). In addition to helping researchers understand issues such as terrorism (Conway \& Conway, 2011; Conway et al., 2011; Houck et al., 2017), strategic communication (Conway et al., 2008; Repke et al., 2018; Zubrod et al., 2021), and popular culture (e.g., McCullough, 2019), integrative complexity has proven vitally important in understanding political leadership. For example, political leaders' 
integrative complexity is tied to success in gaining and keeping power (Conway et al., 2012; Suedfeld \& Rank, 1976; Tetlock, 1981), subsequent declarations of war (Suedfeld, Tetlock, \& Ramirez, 1977; Suedfeld \& Jhangiani, 2009; Tetlock, 1985; see Conway et al., 2001; Conway et al., 2018, for reviews), charisma (Wasike, 2017), and political ideology (Conway, Gornick et al., 2016; Conway, Houck et al., 2016; Houck \& Conway, 2019; Suedfeld, 2010; Tetlock, 1983).

\section{The Complexity of Biden and Trump: Available Evidence to Date}

What do we know so far about the complexity of Biden's and Trump's actual rhetoric (as opposed to public perception of their rhetoric)? Surprisingly, little research to our knowledge has scored Joe Biden or Donald Trump for integrative complexity, with only one study that generally revealed Trump had relatively low complexity (but without a rich historical comparison context; Conway et al., 2020). However, Trump has been scored for conceptually related variables. For example, evidence from the presidential primaries suggests Trump used a very informal communication style - a style that might imply low complexity (Ahmadian et al., 2017). Further, prior evidence using Linguistic Inquiry and Word Count's (LIWC) analytic thinking measurement suggests that, while Trump is indeed lower than the normal president for analytic thinking, this is in part a continuation of a recent temporal trend for presidents to be ever lower in that construct (Jordan \& Pennebaker, 2017; Jordan et al., 2019).

These data are informative of Trump's rhetoric more generally, but for our present question, they are merely suggestive. It is worth noting that LIWC's complexity-related scores, while conceptually related to human-scored integrative complexity, are generally not very correlated with it (in one set of validity studies, average $r=.14$; Conway et al., 2014). As a result, in the present study, we evaluate Trump using a method designed to 
be a more direct measurement of integrative complexity. Further, unlike prior work using LIWC (Jordan et al., 2019), we evaluate both Trump and Biden against a larger historical context, both across parties and within their own party.

\section{Material Selection}

While it is tempting to simply use all available materials for each president across time as a historical comparison, doing so often yields inconclusive or spurious results because what is gained in additional materials is lost in lack of comparison precision. Indeed, less is often more: By limiting the range of materials to only those that can be reasonably compared, scientists hone in on the real nature of effects more clearly (see Houck \& Conway, 2019, for more detail about this argument).

Thus, to better understand Biden's and Trump's complexity in historical context, our approach was to place the two presidents in that historical context on materials that (a) could be scored for U.S. presidents for at least the last 50 years, and (b) maintained a somewhat similar format and parameters over time. Three different kinds of materials met these criteria: (1) Pre-election Presidential Debates, (2) Post-Election Inauguration Speeches, and (3) Post-election State of the Union speeches. We focus on these three key kinds of source materials because each provides a clear, scientifically-valid comparison group. This allows us to focus on these two questions: (1) Compared to other presidents, how complex are Biden and Trump on each of these three kinds of materials? (2) Is the complexity of Biden and Trump reflective of larger historical trends in U.S. presidential complexity, or do they stand out as unique outliers?

\section{Methods}

\section{Automated Integrative Complexity}


In 2014, Conway and colleagues introduced the Automated Integrative Complexity scoring system (AutoIC), a natural language processing system (see Boyd \& Schwartz, 2021, for a discussion) which was specifically designed by integrative complexity researchers to measure that construct (Conway et al., 2014; Houck et al., 2014). The AutoIC system scores differentiation (distinguishing different dimensions) and integration (the recognition of the interplay of differentiated dimensions) in the same hierarchical fashion as the human-scored IC system. In the original validity paper, AutoIC showed higher overall and prospective correlations (that is, correlations on new materials) with expert human scorers than other attempts to automate the construct (average overall $r=.46$; average prospective $r=.41$; Conway et al., 2014). Further, AutoIC replicated effects from human-scored IC in the Bush/Kerry debates, Obama/McCain debates, early Christian writings, and smoking/health domains (Conway et al., 2014).

Since the original paper, validity evidence for AutoIC has grown (see Conway et al., 2020, for a summary). Additional studies have compared expert human scorers to AutoIC and shown continued positive results - indeed, in each case, the human-AutoIC correlation was greater than in the original Conway et al. (2014) paper (Conway et al., 2020; Houck et al., 2018; McCullough \& Conway, 2018a; Prinsloo, 2016). Further, AutoIC has been used in multiple studies across a wide variety of domains to produce theoretically-interpretable findings, including in the domains of organizational science (Mell et al., 2021), forecasting (Karvetskia et al., in press), terrorism (Houck et al., 2017; Putra et al., 2018), fictional versus real dialogue (McCullough \& Conway, 2018a), decision-making (Prinsloo, 2016), the film industry (McCullough \& Conway, 2018b), video game dialogue (McCullough, 2019), fan fiction (McCullough, 2019), religion 
(Houck et al., 2018), social media (McCullough \& Conway, 2019), and trial outcomes (Zubrod et al., 2021). Also, a recent set of studies revealed that AutoIC showed similar across-domain and across-time correlations as human-scored IC (Conway \& Woodard, 2019). In addition, in the most recent attempt to validate AutoIC (Conway et al., 2020), AutoIC successfully replicated prior hand-scored IC studies across several domains, such as health, ideology, and presidential leadership.

Unlike human scoring (where, due to time and labor constraints, only a small subset of materials can be scored), AutoIC scores all of the selected material from each candidate/president. In the present study, for each speech or debate, we scored materials separately for each candidate (removing all dialogue from the other candidates and/or the moderator). AutoIC automatically divides each speech/debate into paragraphs of equal word length and provides a score for each paragraph.

\section{Presidential Debates}

Since 1960, most presidential elections (and all since 1976) have had at least two debates. Using these debates as primary source materials allows us to see how Biden and Trump compare to typical presidents (that is, those who ultimately won election) during the same temporal period prior to the election.

For Trump, we further compared him to other concurrent candidates during his own 2015-2016 Republican Primaries debates, as well as computed pre/post-election comparisons for his debates that occurred before and after becoming president. As we will see below, each of these comparisons generally point to the same conclusion.

\section{SOTU Speeches}

For post-election, we compared Biden and Trump against the most standardized (and also most studied and validated) historical baseline speech for evaluating U.S. 
Presidents: The State of the Union (SOTU) speech. Due to a standardized timing and format (see Thoemmes \& Conway, 2007), SOTU speeches provide a fairly consistent baseline of other presidents to compare Biden and Trump against. ${ }^{1}$

\section{Inaugural Speeches}

Additionally, we compared Biden and Trump against another standardized historical baseline speech for evaluating U.S. Presidents: The Inaugural Address. An inaugural address is given after a president has been sworn into office and has been given by every elected U.S. president since George Washington (Peters, n.d.). Similar to SOTU speeches, inaugural addresses provide a fairly consistent baseline to compare presidents over time.

\section{Political Ideology}

Republican elected officials tend to be less integratively complex than Democratic elected officials (for meta-analytic evidence, see Houck \& Conway, 2019). As a result, we also performed within-party analyses for both Biden and Trump on all key tests. Because political ideology is a shifting standard (see Conway et al., 2021) and the specific political ideologies of "republican" and "democrat" have changed over time (see, e.g., Luks \& Elm, 2005), for all ideology analyses, we opted to remove any data that occurred before 1960 for these tests. As seen below, those tests almost uniformly showed similar results to those that combined across party lines.

\section{Analytic Strategy}

Mean Comparisons and Segmented Regression. Our general analytic approach was to first compare Biden and Trump separately to the sum of all other

\footnotetext{
${ }^{1}$ Generally, first-year addresses to Congress are considered equivalent to SOTU speeches. For Biden, at this point we only have one SOTU-equivalent speech, given April 28, 2021.
} 
presidents on each material type. This allowed us to establish, generally speaking, how each president fared compared to the average president over American history. Then, using modern segmented regression techniques (Jebb et al., 2015; Schaller et al., 2017) described in more detail below, we attempted to determine the degree that Biden's and Trump's complexity scores were an extension of historical trends (for each type of material separately) versus instead being unique outliers that stood out against a historical background.

Analytic Strategy for Inclusion/Exclusion. Our inclusion/exclusion strategy was conceptually straightforward: We attempted to use comparable materials among presidents except when additional data were needed for temporal analyses. Thus, for comparing Biden and Trump to each other, we used all available material across the three categories. For mean comparisons of Biden and Trump to the average president, we compared prior presidents' speeches/debates from the first term only, because Biden and Trump had first-term (but not second-term) materials. Further, to ensure similar comparisons between presidents, in all mean comparisons that evaluated Biden compared to historical context, we excluded Trump (and vice versa). However, when performing segmented regression analyses that controlled for temporal variables, we included all available data from each Presidential source for each analysis (for example, we included both terms for multiple term presidents and included Biden in Trump's timeline and vice versa). That is because, for those analyses, we deemed it more important to have all the available data in the timeline. As seen below, these conceptually-driven exclusion approaches yielded a very coherent story across analysis type. 
Unit of Analysis. As in much prior research scoring U.S. presidents' archival materials using integrative complexity (e.g., Conway et al., 2012; Conway et al., 2020; Repke et al., 2018; Thoemmes \& Conway, 2007), we used the paragraph as the unit of analysis. While this approach conveys many advantages (see, e.g., Cohen, 1990, for a discussion about the potential advantages of using finer-grained units of analyses, which helps avoid unnecessary losses of power), it also almost certainly radically underestimates effect sizes (for examples and discussion, see Conway et al., 2020; Woodard et al., 2021). Because effect sizes proportionally increase with larger aggregated units of the same data (Conway et al., 2020), this means that effect size estimates here should not be viewed as the true effect size. Rather, those effect sizes should be used for comparison within this study only, and recognized as likely representing vast underestimates. In footnote 3 below, we provide one direct illustration of this principle by showing what the effect sizes would look like at larger levels of aggregation.

\section{Results}

\section{Biden's and Trump's IC Scores Compared To Each Other}

Comparing Biden and Trump to each other, a 3 (Document Type: Debates Versus SOTU Versus Inauguration) X 2 (President: Biden Versus Trump) ANOVA revealed that Biden and Trump did not significantly differ from each other on integrative complexity (overall IC Biden $M=1.72$; overall Trump $M=1.74 ; F[5,1065]=1.38, p=.241$ ). The document type X president interaction approached, but did not attain, statistical significance $(p=.075)$. Evaluating each document type separately, the two candidates were similar on SOTU speeches (Biden $M=1.71$, Trump $M=1.66$; comparison $p=$ .604). Trump was higher on debates overall (Biden $M=1.70$, Trump $M=1.80$ ), a 
difference that approached statistical significance $(F[1,662]=3.52, p=.061) .{ }^{2}$ Biden was higher in complexity on the inaugural speech (Biden $M=1.83$, Trump $M=1.51$ ), but due to smaller sample sizes, this difference did not approach statistical significance $(p=$ $.204)$.

\section{Biden's and Trump's IC Scores Compared To Historical Context}

Biden. We placed Biden's scores in historical context by comparing him to all other presidents (excluding Trump) via a 3 (Document Type: Debates Versus SOTU Versus Inauguration) X 2 (President: Biden Versus Others) ANOVA. These analyses revealed that Biden was much lower overall than the typical president (overall IC Biden $M=1.72$; Presidential $M=2.06 ; F[1,23558]=19.20, p<.001 ; d=.06, L C I=.03, U C I=.08)$. As can be seen in Figure 1, these effects were very similar for Biden across document types, a fact supported by the lack of a significant document type X Biden interaction (interaction $p=.598$ ). Follow-up analyses revealed that Biden was significantly lower than the historical baseline for both Debates and SOTU speeches computed separately $\left(F^{\circ} \mathrm{S}>11.0, p\right.$ 's $\left.=<.001\right)$. However, although the mean difference for inauguration speeches was roughly equivalent to the other two types (see Figure 1), a lower sample size for those speeches meant that the difference for inauguration speeches approached, but did not attain, statistical significance for Biden $(p=.098)$.

We further compared Biden to his own party (Democrats) since 1960, and the results were virtually identical to those for the whole sample: Biden was significantly lower than his fellow Democrats overall $(p<.001)$, and this was equivalently so across all three document types (interaction $p=.813$ ).

${ }^{2}$ This difference was almost entirely driven by Trump scoring higher in his 2016 Presidential debates - in their mutual 2020 debate, Biden $(M=1.70)$ and Trump $(M=1.73)$ had nearly identical complexity levels. 


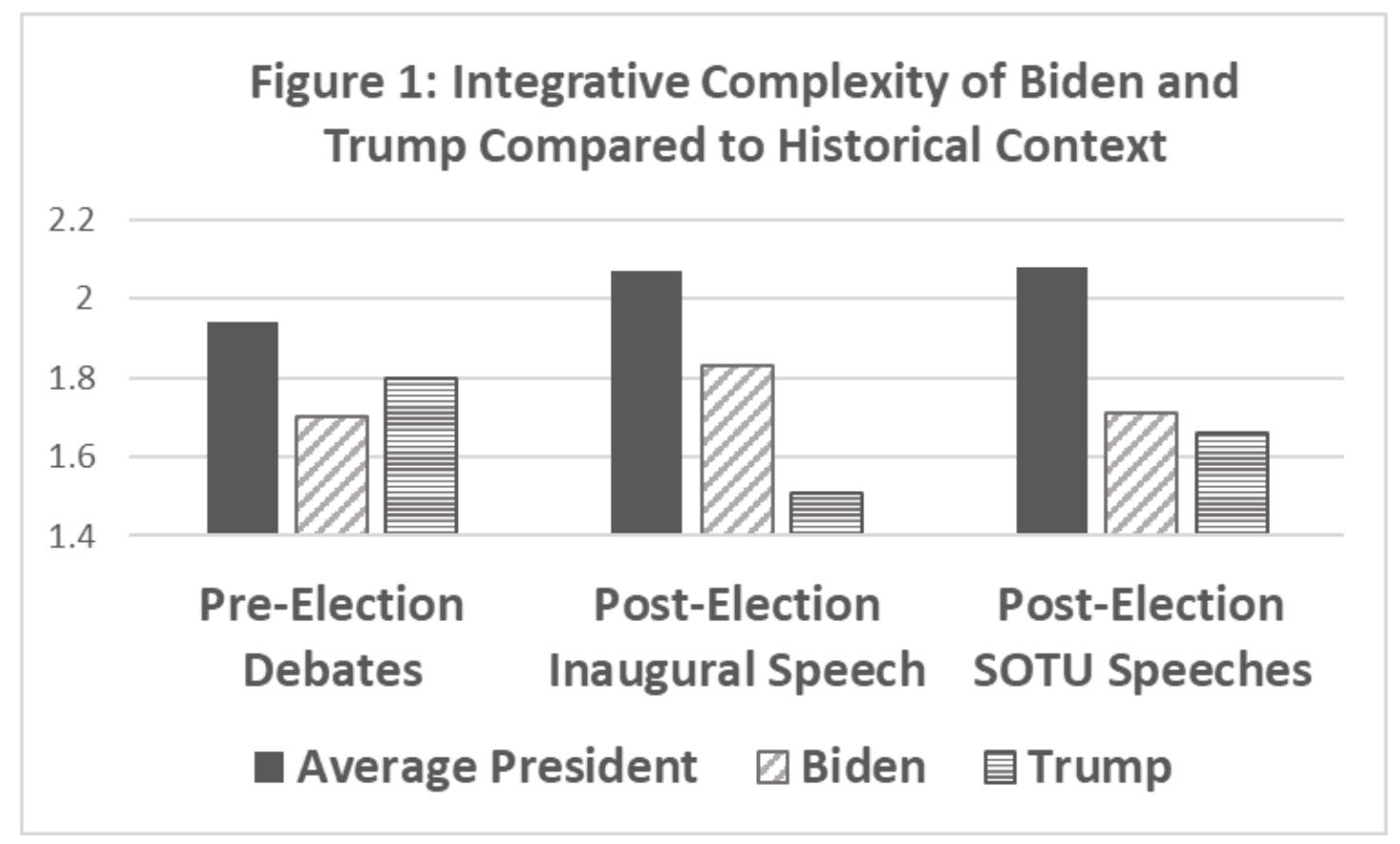

Trump. We similarly placed Trump's scores in historical context by comparing him to all other presidents (excluding Biden) via a 3 (Document Type: Debates Versus SOTU Versus Inauguration) X 2 (President: Trump Versus Others) ANOVA. These analyses revealed that Trump was much lower overall than the typical president with an effect size essentially identical to Biden (overall IC Trump $M=1.74$; Presidential $M=2.06$; $F[1,24071]=20.471, p<.001 ; d=.06, L C I=.03, U C I=.08)$. However, unlike for Biden, the effects were not the same for each document type, as indicated by a significant document type X Trump interaction (interaction $F[2,24071]=7.43, p<$ .001). Although follow-up analyses revealed that Trump was significantly lower than the historical baseline for all three document types computed separately ( $F$ s $>$ 7.0, $p$ 's $<$ .01), Figure 1 descriptively suggests that the significant interaction was due to Trump's higher pre-election complexity scores (compared to a historical baseline) than for both post-election measures - but especially as compared to his (extremely low) inauguration speech. 
We further compared Trump to only persons in his own party (Republicans) since 1960, and the results were virtually identical to those for the whole sample: He was lower overall $(p<.006)$ than other Republicans, and an interaction emerged (interaction $p=.006$ ) revealing he was especially low compared to other Republicans on post-election measures (again, particularly so for his inauguration speech).

Additional data allowed for further comparisons for Donald Trump that were not performed for Biden. First, we compared the change in Donald Trump's debates from pre-election (when he ran as a challenger) to post-election (when he ran as an incumbent) relative to other Presidents who had similar pre-election (challenger) and post-election (incumbent) debates. These 2 (Pre-Election Versus Post-Election debates) X 2 (Trump Versus Others) results spoke very clearly: Whereas other Presidents did not drop in complexity for post-election debates (Pre-Election $M=1.93$, Post-Election $M=$ 1.96), Trump dropped notably after being elected (Pre-Election $M=1.84$, Post-Election $M=1.73)$, interaction $F(1,2877)=3.96, p=.047$.

We further compared Trump to the other candidates (both Democratic and Republican) during the 2015-2016 Primary Debates. These comparisons reveal that Trump was descriptively slightly lower than the average candidate, but this difference did not approach statistical significance (Average Candidate Debate IC $=1.85$; Average Trump Debate IC $=1.80 ; F[1,5344]=1.59, p=.208 ; d=.03[95 \% L C I=-.02, U C I$ $=.09])$. This gap was even smaller when comparing Trump to the other Republican candidates during the primary season (Average Republican Debate IC $=1.81$; Average Trump Debate IC $=1.80 ; F[1,3699]=0.08, p=.783 ; d=.01[95 \% L C I=-.06, U C I$ $=.07])$. These additional analyses on Trump corroborate the main analyses: That, while Trump was not especially complex during the campaign season (a range that could be 
described as "average" to "somewhat below average"), he became extremely low in complexity after taking office.

\section{Are Biden and Trump's Low Complexity Part of an Overall Historical Trend?}

Thus far, this set of comparative data suggests that both Biden and Trump are historically low in integrative complexity at roughly equal levels, both compared to a larger historical context and to a more focused historical context of their own party. They further suggest that whereas Biden's complexity remained at a fairly stable (albeit low) level, Trump's complexity started higher pre-election and then plummeted postelection.

But why are these two presidents' scores so low? Specifically, is it possible that these low scores are not unique to them, but are instead a continuation of a downward historical trend for U.S. presidential complexity (see, e.g., Jordan et al., 2019)?

To better understand the historical context within which Biden and Trump's scores are placed, we first computed overall historical trends on all three material types. These overall historical trends (both including all data and data reflecting only more recent historical trends since 1960) suggest that complexity of all three document types was decreasing over time. However, this trend was most clearly in evidence for SOTU speeches: year of speech inversely and significantly predicted integrative complexity for SOTU speeches (overall beta[27772] $=-.07, p<.001$; since 1960, beta[6288] $=-.15, p<$ .001), showed a nearly significant trend for Debates (beta[3928] $=-.03, p=.052)$, and a 
negatively sloping (but not statistically significant) trend for inauguration speeches $(b e t a[1770]=-.03, p=.229 ;$ since 1960, beta $[399]=-.04, p=.428) .3$

To understand the degree that Biden's and Trump's low scores might be an extension of a historical downward trend (versus unique outliers), we performed segmented regression analysis (see, e.g., Jebb et al., 2015). Segmented regression analysis has been described as a "statistically elegant" means to evaluate the degree that a particular categorical variable is a continuation of a linear trend or is different from that trend (Schaller et al., 2017, p. 1362). To perform this technique, scientists generally produce (a) a dummy variable representing the category, (b) a variable representing the passage of time throughout the duration studied, and (c) a variable representing the passage of time since the onset of the category in question (Jebb et al., 2015).

In this case, (a) we used a binary variable representing either Donald Trump ( $1=$ Trump, $\mathrm{o}=$ others $)$ or Joe Biden ( $1=$ Biden, $\mathrm{o}=$ others), respectively. (b) For the passage of time throughout the duration, we used the year a particular speech/debate occurred. (c) Due to different levels of information for Biden and Trump, we were forced to use different approaches for each president pertaining to the passage of time since the onset of the category. For Donald Trump, following prior researchers (e.g., Schaller et al., 2017), we assigned all materials prior to his first scored observations (in 2016) a o, and then, starting at one in 2016, incrementally increased the year after that by one (so

\footnotetext{
3 In line with other researchers' observations (see Conway et al., 2020, for discussion), effect sizes in our study are generally much larger if one uses larger aggregations for units of analysis. For example, aggregating each president's materials by year (instead of by paragraph), the effect size of the time drop from 1960 to the present was $r=-.80$ for SOTU speeches, $r=-.29$ for Debates, and $r=-.52$ for Inauguration speeches. This illustrates the danger of estimating effect sizes in large datasets based only on one unit of analysis - such effect sizes arbitrarily shift downwards when, as we have done, scientists choose to use the smallest unit for analysis (and arbitrarily shift upwards the larger the unit of analysis becomes).
} 
$2017=2,2018=3$, etc.). For Joe Biden, a variable representing the passage of time since the event was impractical due to almost no variability post-category, and thus for Biden we only included a variable for Biden ("a" above) and the year ("b" above).

To focus on recent historical trends that had consistent years across materials, we performed this analysis on data since 1960. This segmented regression technique revealed that Donald Trump showed a significant break from historical trends only for his inauguration speech, as illustrated by a significant effect of the Trump variable ("a" above) on inauguration speech complexity, Trump standardized beta[399] $=-.13, p=$ .017. However, his lower IC scores on SOTU speeches (Trump standardized beta[6288] $=-.02, p=.316)$ and debates (Trump standardized beta[3928] $=-.03, p=.195$ ) were subsumed by downward historical trends. 4

Similar segmented regression models revealed Joe Biden showed a significant break from historical trends only for the debates (Biden standardized beta[3928] $=-.06, p<$ .001), as both his inauguration speech (Biden standardized beta[399] $=-.05, p=.426$ ) and SOTU speeches (Biden standardized beta[6288] $=-.00, p=.947$ ) were not

\footnotetext{
4 Almost identical results occurred when evaluating Republican Party presidents only. Since 1960, Republicans showed a significant downward trend in the debates (standardized beta $=-.05, p<.007$ ) and SOTU speeches (beta $=-.20, p<.001)$, but not the inauguration speeches $(p>.780)$. As with the whole sample, segmented regression models revealed Donald Trump showed a significant break from historical trends only for the inauguration speeches (Trump standardized beta $=-.25, p=.004$ ), and both his debates and SOTU speeches did not show significant effects when accounting for historical trends among Republicans ( $p$ 's >.20).
} 
significantly predicted by the Biden variable when controlling for downward historical trends.5,6

These additional analyses suggest that part of the reason Biden and Trump were low in complexity was the continuation of already-existing downward historical trends. However, it further suggests that for each president, part of their low complexity was unique to them and stood out against that historical background. For Biden, his low complexity was especially unique for the pre-election debates; for Trump, his low complexity was especially unique for his post-election inauguration speech.

\section{Discussion}

Taken together, our study reveals that Biden and Trump were historically low in complexity compared to the typical president. That finding holds true whether they are compared to a larger historical context or a narrower context consisting of their own party. It further reveals that the two presidents showed differential variability across types of materials: Biden's complexity remained at a stable low level, while Trump showed higher complexity for the debates than he did for both post-election speeches and particularly for his inauguration speech.

Below, we discuss why Biden and Trump were historically low in complexity, some limitations of our findings, and offer a brief concluding comment.

\section{Why are Biden and Trump's Scores So Low?}

\footnotetext{
5 Almost identical results emerged when evaluating Democratic Party presidents only. Since 1960, Democrats showed a significant downward trend in SOTU speeches (standardized beta $=-.11, p<.001$ ), a non-significant downward relationship inauguration speeches (standardized beta $=-.08, p=.284$ ), and essentially no relationship for the debates $(p>.80)$. As with the whole sample, segmented regression models revealed Joe Biden showed a significant break from historical trends only for the debates (Biden standardized beta $=-.12, p<.001)$ as both his inauguration speech and SOTU speeches did not show significant effects when accounting for historical trends among Democrats ( $p$ 's >.320).

${ }^{6}$ We also computed debate trends via segmented regression using all debate materials - and not just those from Presidents who won elections - and found essentially identical results (both inferentially and descriptively) as those reported in the text on the more comparable sample.
} 
In considering why Biden and Trump's scores are so low, we first consider factors that might apply roughly equally to both of them, and then discuss factors that might be unique to them in turn.

Factors Shared By the Two Presidents. It is clear from our segmented regression results that part of the reason the two most recent U.S. presidents were low in integrative complexity involved a continuation of downward historical trends. We found - as other research (Jordan et al., 2019) found using a different marker of complexity - that American presidents have been declining in complexity before either Trump or Biden took office. The two presidents under the microscope here are, in part, a continuation of that trend.

This is particularly noticeable for SOTU speeches. Both Biden and Trump showed overwhelmingly significantly lower integrative complexity than the average president ( $p$ 's $<.001)$. However, for both presidents, this negative effect was largely wiped out and became non-significant - when accounting for the historical downward trend. This suggests (as other work using a different complexity marker also suggests; Jordan et al., 2019) that in the case of SOTU speeches, both presidents were part of a downward trend that had pre-existed before either took office.

What might account for this downward trend? While it is hard to know for sure, it is possible that increasing political polarization (which has reached record levels) over the past three decades might have contributed to a more gradual decline in U.S. political figures' communication complexity. This might alter presidential complexity for strategic communication reasons (e.g., Conway et al., 2018; Houck \& Conway, 2019; Repke et al., 2018; Tetlock, 1981). Research suggests, for example, that playing to a singular (versus a divided) audience can alter some forms of complexity in strategic 
ways (Repke et al., 2018). That research would suggest that dialectical complexity (i.e., which recognizes competing perspectives) in the present case should be particularly affected by polarization as politicians increasingly tailor their message to please their own partisans - a hypothesis not tested in the present study - and that such strategic factors might help explain this downward shift.7

It is also possible that the job itself has become more taxing, and thus the lower complexity reflects increased cognitive fatigue or other cognitive factors. Not only is a polarized country more stressful, the media (including the increasing influence of social media) has made the presidency a $24 / 7 \mathrm{job}$. As such, it is possible that there is something more like a cognitive shift as modern presidents do not have as much effort or energy to spend on any one speech (for discussions of the cognitive effects of stress in politics, see Suedfeld, 1992).

Factors that Differed Between the Two Presidents. Although Biden and Trump clearly shared more similarity than differences in their integrative complexity, they nonetheless showed some marked differences. We note two things in particular. First, whereas Biden showed little variability across the three types of materials, Trump was markedly higher in the complexity of his debates versus the other two types (with Trump's inauguration speech especially low in complexity). Secondly, and complementarily, whereas Biden stood out against a historical background for the

\footnotetext{
7 It is also worth noting that the two presidents could be construed as having shared a time period that itself is an outlier for political polarization. As such, it is possible that even the part of their complexity that remains after accounting for historical trends could be due to a shared polarized environment that began around the time Trump rose to power. Of course, this would not explain the fact that they were historical outliers on different types of materials, but it could nonetheless explain part of the context that produced more generally such low levels of complexity.
} 
debates, Trump stood out especially for his inauguration speech. What are we to make of these differences?

Our data cannot definitively answer this question, but they nonetheless might offer some clues to ponder. To help place these differences in a scientific framework, we turn to personality research on complexity. A recent large review of the complexity literature suggested that complexity could be viewed as a trait that accounts for a small-tomoderate amount of variance (Woodard et al., 2021). Further, that review suggested that two larger factors contributed roughly equally to the complex (or simple) person: Motives and abilities (Woodard at al., 2021). We use these two guideposts to suggest possible interpretations of the two presidents' specific differences.

Trump's low complexity is most notable - and significantly stands out the most against a historical background - for his inauguration speech. Indeed, even descriptively, Figure 1 reveals how unusual Trump is in this regard. A great deal of research and theory suggests that political leaders of all stripes - and especially successful political leaders - tend to be lower in complexity before attaining power and then rise in complexity after coming to power (Suedfeld, 1992; Suedfeld \& Rank, 1976; Tetlock 1981). And indeed, in our own data, the average president fit this pattern, with both post-election scores higher than the pre-election debates. As Figure 1 shows, however, Donald Trump - despite clearly being capable of producing at least average levels of integrative complexity - defied this trend and actually dropped markedly in complexity post-election. (Notably, Biden did not drop in complexity post-election; see Figure 1). While as we have discussed, part of this for the SOTU speeches is explained by ongoing trends that are not captured in Figure 1, nonetheless his descriptive pattern combined with the historical outlier status of his inauguration speech - is striking. 
While of course it is hard to know why such a shift occurred, we suspect it does not reflect an inability of Donald Trump to rise above very simple rhetoric, but instead reflects his own motive profile. This is for two reasons. (1) His performance during both the primary debates and the pre-election presidential debates - which are more unscripted - suggests a capability to produce a level of complexity that is consistently closer to "slightly below average" than "incredibly low." (2) His motive profile likely reflects someone more likely to show very low complexity once having achieved the strategic goal of gaining power. Winter (2018) examined Trump's 2017 inaugural speech for motive imagery, and found that, relative to other 20th and 21st century U.S. presidents, Trump scores high in power motive and average in affiliation motive. Prior work suggests that this motive profile is likely associated with lower complexity: Affiliation-related motives and traits tend to be positively related to integrative complexity (e.g., Conway et al., 2020; Coren \& Suedfeld, 1995; Thoemmes \& Conway, 2007; Winter, 2007; see Woodard et al., 2021, for a summary), whereas power motives tend to be unrelated or negatively related (e.g., Thoemmes \& Conway, 2007; Winter, 2007). Further, evidence reveals that a high power to affiliation ratio predicts aggressive foreign policy decisions from politicians holding office in much the same manner as low integrative complexity predicts aggression (e.g., Winter, 2003), suggesting a shared psychology between a high power/low affiliation motive profile and low integrative complexity that may be especially likely to occur once people hold power.

It is possible, then, that his especially low post-election complexity scores - and in particular those for his inauguration speech (which was the one scored by Winter for his motive profile) - are related to his motives immediately after taking office. Indeed, such an explanation dovetails with subjective narratives about his immediate post-election 
speeches, with his inaugural speech in particular receiving attention for being especially angry, dark, aggrieved, and defiant (Barabak, 2017; Page, 2017), even listing domestic enemies (Lundberg \& Gunn, 2017). Thus, it is possible that Trump, relative to the average president, was more motivated by power than by motives to talk of peace and unity (i.e., affiliation) in his post-election speeches, and that might have driven down his integrative complexity scores even more than the historical trend for inaugural speeches would predict.

Biden, on the other hand, showed fairly stable low complexity across all three material types. Notably, however, the one type on which he stood out as uniquely low against a historical background was the debates. Again, we do not know why this is the case for certain, but one possibility is that suggestions of his cognitive decline (e.g., Thiessen, 2020) were partially accurate. We know cognitive ability is related to linguistic complexity (Woodard et al., 2021). As a result, one possible interpretation is that the post-election speeches could be scripted and read, whereas the debates are comparatively more unscripted. Thus it is possible that the debates showed lower complexity for Biden compared to the historical context because that is the place cognitive decline would most likely be in evidence for integrative complexity scores.

Of course, for both Biden and Trump, all such personality associations are indirect and must be taken as speculations only. It is equally possible that these differences reflect some situation-contingent circumstances, random variance, or ability or motivations we haven't ascribed correctly. What is clear is that the two presidents, in each his own way, stood out against a historical background for one of the types of materials - and that material type differed for each president.

\section{Limitations}


Although the current study provides novel evidence of the complexity of Biden and Trump's actual rhetoric - evaluating them across parties, within their own party, and against the larger historical context - it is not without limitations. First, like other studies that evaluate political figures, researchers do not have access to all the private thoughts of these individuals. For instance, the declining mental health and eventual suicide of James Forrestal was a shock to the nation after he left office in 1949 because it was in stark opposition to his public image as the nation's first Secretary of Defense (Historical Office, n.d.). Thus, it can be hard to interpret at-a-distance measures. Although it is noteworthy that integrative complexity reduces biases often associated with self-report measures (e.g., Jost et al., 2003) because it directly scores participant output (Suedfeld et al., 1977). Further, as McCullough and Conway (2018b) suggest, "Linguistic measurements, in general, can provide a potential window into the behindthe scenes psychology of the human experience" (p. 2). Nevertheless, we do not have direct access to the political figures' minds in question, and thus caution against overinterpretation is warranted.

Another shortcoming is the possible assistance of speechwriters in some of these materials (e.g., SOTU speeches). While presidents since Washington have sought aid from speechwriters, Calvin Coolidge was the first to hire a full-time speechwriter (Olinger, 2016). Thus, it is unclear how much of a speech is written by a president and how much aid is given to each president (Beard, 2000). However, former presidential speechwriter Ted Sorensen and other speechwriters suggest speechwriters act as mere agents who help presidents best express themselves through the study of their linguistic patterns, ideas, and polices (Olinger, 2016). Furthermore, as illustrated in a previous study examining the first 41 U.S. presidents' first four SOTU speeches, speechwriting 
contributed little to integrative complexity results (see Thoemmes \& Conway, 2007, for a summary).

Additionally, these results do not explain linguistic trends in other governmental political leaders in the U.S. or other world leaders - these results only apply to the U.S. presidential context. Thus, future research is needed to examine other political contexts and types of political leaders, a limitation increasingly important as we seek to uncover similarities and differences across cultures (see Henrich et al., 2010). It remains to be seen if this downward historical trend in complexity for U.S. presidents might extend beyond the U.S. to other culturally-similar locales and/or even very different cultural locales.

\section{Concluding Thoughts}

People are often motivated to see what they want to see. This is rarely more true than in a divided political landscape. American media outlets often associate high morality with their preferred political candidate, regardless of their actual moral traits (for example, Trump or Clinton in the 2016 election; Bhatia et al., 2018). American culture has been reticent to believe climate science, despite very high scientific consensus on the topic (see Conway et al., 2021, for a summary). Americans often believe that religious people are simple-minded, but evidence on the actual complexity of religious persons tells a more complicated story (see Houck et al., 2018). Just because popular culture believes something is true, that does not make it so.

However, popular perception is not always wrong. As such, the present results suggest the importance of scientific evaluations of popular ideas. The popular perception of Donald Trump is that he uses simple rhetoric, and our scientific study of his actual rhetoric reveals that this perception is largely correct. On the other hand, the 
popular perception of Joe Biden is much less unilateral with respect to his complexity and yet our data suggest he is, on average, just as simple as Donald Trump. These facts do not mean that Trump was or Biden is necessarily a bad (or good) president - neither high nor low complexity are universally good or bad (see Conway et al., 2018). Indeed, such normative judgments are beyond the scope of our scientific article. However, in the modern political climate, it is important to separate fact from fiction - and the present results provide triangulating evidence that both Joe Biden and Donald Trump are consistently lower in complexity than other historically-valid comparison groups - and further suggests some reasons why that is the case. Both Biden and Trump are partially caught in an ongoing decline in American Presidential complexity; but they are both also uniquely simple against that background in different ways. 


\section{References}

Abe, J. A. A. (2011). Changes in Alan Greenspan's language use across the economic cycle: A text analysis of his testimonies and speeches. Journal of Language and Social Psychology, 3o, 212-223. http://dx.doi.org/10.1177/0261927X10397152

Abe. J. A. A. (2012). Cognitive-affective styles associated with position on war. Journal of Language and Social Psychology, 31, 212-222.

Ahmadian, S., Azarshahi, S., \& Paulhus, D. L. (2017). Explaining Donald Trump via communication style: Grandiosity, informality, and dynamism. Personality and Individual Differences, 107, 49-53. https://doi.org/10.1016/j.paid.2016.11.018

Akst, D. (2019, July 3). Trump's advantage is that he has a story to tell. LA Times. https://www.latimes.com/opinion/op-ed/la-oe-akst-trump-election-democrats20190703-story.html

Atkins, D. (2018). Trump is a simple-minded bully who knows only one tactic. Washington Monthly. https://washingtonmonthly.com/2018/o3/17/donaldtrump-is-a-simple-minded-bully-who-only-knows-one-tactic/

Barabak, M. Z. (2017, January 20). Analysis: Raw, angry and aggrieved, President Trump's inaugural speech does little to heal political wounds. LA Times. https://www.latimes.com/politics/la-na-pol-trump-inauguration-speechanalysis-20170120-story.html

Beard, A. (2000). Language of Politics. Routledge.

Bhatia, S., Goodwin, G. P., \& Walasek, L. (2018). Trait associations for Hillary Clinton and Donald Trump in news media: A computational analysis. Social Psychological and Personality Science, 9(2), 123-130. https://doi.org/10.1177/1948550617751584 
Blair, G. (2016, November 11). Inside the mind of Donald Trump. The Guardian. https://www.theguardian.com/us-news/2016/nov/12/inside-the-mind-ofdonald-trump-biographer-gwenda-blair

Boyd, R. L., \& Schwartz, A. H. (2021). Natural language analysis and the psychology of verbal behavior: The past, present, and future states of the field." Journal of Language and Social Psychology, 40, 21-41.

Carmon, I. (2016, August 10). Donald Trump's worst offense? Mocking disabled reporter, poll finds. NBC News. https://www.nbcnews.com/politics/2016election/trump-s-worst-offense-mocking-disabled-reporter-poll-finds-n627736

Cohen, J. (1990). Things I have learned (so far). American Psychologist, 45(12), 13041312. https://doi.org/10.1037/0003-066X.45.12.1304

Conway, L. G., Chan, L., Woodard, S. R., \& Joshanloo, M. (2021). Proximal versus distal ecological stress: Socio-ecological influences on political freedom, well-being, and societal confidence in 159 nations. Journal of Social and Political Psychology, 9(1), 306-320. https://doi.org/10.5964/jspp.5927

Conway, L. G., III, \& Conway, K. R. (2011). The terrorist rhetorical style and its consequences for understanding terrorist violence. Dynamics of Asymmetric Conflict, 4(2), 175-192. http://dx.doi.org/10.1080/17467586.2011.627940

Conway, L. G., III, Conway, K. R., Gornick, L. J., \& Houck, S. C. (2014). Automated integrative complexity. Political Psychology, 35(5), 603-624. https://doi.org/10.1111/pops.12209

Conway, L. G., III, Conway, K. R., \& Houck, S. C. (2020). Validating Automated Integrative Complexity: Natural language processing and the Donald Trump test. 
Journal of Social and Political Psychology, 8(2), 504-524. https://doi.org/10.5964/jspp.v8i2.1307

Conway, L. G., III, Gornick, L. J., Burfiend, C., Mandella, P., Kuenzli, A., Houck, S. C., \& Fullerton, D. T. (2012). Does simple rhetoric win elections? An integrative complexity analysis of U.S. presidential campaigns. Political Psychology, 33(5), 599-618. https://doi.org/10.1111/j.1467-9221.2012.00910.x

Conway, L. G., III, Gornick, L. J., Houck, S. C., Hands Towgood, K., \& Conway, K. R. (2011). The hidden implications of radical group rhetoric: Integrative complexity and terrorism. Dynamics of Asymmetric Conflict, 4(2), 155-165. http://dx.doi.org/10.1080/17467586.2011.627938

Conway, L. G. III, Gornick, L. J., Houck, S. C., Anderson, C., Stockert, J., Sessoms, D., \& McCue, K. (2016). Are conservatives really more simple- minded than liberals? The domain specificity of complex thinking. Political Psychology, 37(6), 777-798. https://doi.org/10.1111/pops.12304

Conway, L. G., III, Houck, S. C., Gornick, L. J., \& Repke, M. A. (2016). Ideologicallymotivated perceptions of complexity: Believing those who agree with you are more complex than they are. Journal of Language and Social Psychology, 35(6), 708-718. https://doi.org/10.1177/0261927X16634370

Conway, L. G., III, Repke, M. A., \& Houck, S. C. (2017). Donald Trump as a cultural revolt against perceived communication restriction: Priming political correctness norms causes more Trump support. Journal of Social and Political Psychology, 5(1), 244-259. https://doi.org/10.5964/jspp.v5i1.732

Conway, L. G., III, Suedfeld, P., \& Tetlock, P. E. (2018). Integrative complexity in politics. In A. Mintz (Ed.), Oxford Handbook of Behavioral Political Science 
Oxford University Press.

https://doi.org/10.1093/oxfordhb/9780190634131.013.7

Conway, L. G., III., Thoemmes, F., Allison, A. M., Hands Towgood, K., Wagner, M. J., Davey, K., Salcido, A., Stovall, A. N., Dodds, D. P., Bongard, K, \& Conway, K. R. (2008). Two ways to be complex and why they matter: Implications for attitude strength and lying. Journal of Personality and Social Psychology, 95(5), 10291044. https://doi.org/10.1037/aoo13336

Conway, L. G., III, \& Woodard, S. R. (2019). Integrative complexity across domains and across time: Evidence from political and health domains. Personality and Individual Differences, 155. https://doi.org/10.1016/j.paid.2019.109713

Coren, S., \& Suedfeld, P. (1995). Personality correlates of conceptual complexity. Journal of Social Behavior \& Personality, 10(1), 229-242. https://www.proquest.com/openview/c5eb8e959a1cc7bf4368ad81b1aboo84/1?p q-origsite $=$ gscholar\&cbl $=1819046$

Crandall, C. S., Miller, J. M., \& White, M. H., II. (2018). Changing norms following the 2016 U.S. presidential election: The Trump effect on prejudice. Social Psychological and Personality Science, 9(2), 186-192. https://doi.org/10.1177/1948550617750735

Daily Kos (2019, July 1). The simple mind of Donald Trump. Daily Kos. https://www.dailykos.com/stories/2019/7/1/1868751/-The-Simple-Mind-ofDonald-Trump

Dimock, M., \& Wike, R. (2020, November 13). America is exceptional in the nature of its political divide. Pew Research Center. https://www.pewresearch.org/facttank/2020/11/13/america-is-exceptional-in-the-nature-of-its-political-divide/ 
Does, S., Gündemir, S., \& Shih, M. (2019). The divided states of America: How the 2016 U.S. presidential election shaped perceived levels of gender equality. Social Psychological and Personality Science, 10(3), 374-381. https://doi.org/10.1177/1948550618757033

Francia, P. L. (2017). Free media and Twitter in the 2016 presidential election. Social Science Computer Review, 36(4), 440-455. https://doi.org/10.1177/0894439317730302

French, B. (2018). Donald Trump is weak and afraid. The Mueller report proves it. Time. https://time.com/5574118/mueller-report-donald-trump/

Frimer, J. A., \& Skitka, L. J. (2018). The Montagu Principle: Incivility decreases politicians' public approval, even with their political base. Journal of Personality and Social Psychology, 115(5), 845-866. https://doi.org/10.1037/pspioooo140

Henrich, J., Heine, S. J., \& Norenzayan, A. (2010). The weirdest people in the world?. Behavioral and brain sciences, 33(2-3), 61-83

Historical Office. (n.d.). James V. Forrestal, Harry Truman Administration. U.S. Historical Office: Office of the U.S. Secretary of Defense. https://history.defense.gov/Multimedia/Biographies/ArticleView/Article/571293/james-v-forrestal/

Hermann, M. G. (1980). Explaining foreign policy behavior using the personal characteristics of political leaders. International Studies Quarterly, 24, 7-46. https://www.jstor.org/stable/2600126

Houck, S. C., \& Conway, L. G. III. (2019). Strategic communication and the integrative 
complexity-ideology relationship: Meta-analytic findings reveal differences between public politicians and private citizens in their use of simple rhetoric. Political Psychology, 4O(5), 1119-1141. https://doi.org/10.1111/pops.12583

Houck, S. C., Repke, M. A., \& Conway, L. G., III. (2017). Understanding what makes terrorist groups' propaganda effective: An integrative complexity analysis of ISIL and Al Qaeda. Journal of Policing, Intelligence and Counter Terrorism, 12(2), 105-118. https://doi.org/10.1080/18335330.2017.1351032

Houck, S. C., Conway, L. G., III, \& Gornick, L. J. (2014). Automated integrative complexity: Current challenges and future directions. Political Psychology, 35(5), 647-659. https://www.jstor.org/stable/43783810

Jebb, A. T., Tay, L., Wang, W., \& Huang, Q. (2015). Time series analysis for psychological research: Examining and forecasting change. Frontiers in Psychology, 6, Article 727. https://doi.org/10.3389/fpsyg.2015.00727

Jones, J. M. (2021, April 15). Biden sparks greater party, education gaps than predecessors. Gallup. https://news.gallup.com/poll/346622/biden-sparksgreater-party-education-gaps-predecessors.aspx

Jordan, K. N., \& Pennebaker, J. W. (2017). The exception or the rule: Using words to assess analytic thinking, Donald Trump, and the American presidency. Translational Issues in Psychological Science, 3(3), 312-316. https://doi.org/10.1037/tpsoooo125

Jordan, K. N., Sterling, J., Pennebaker, J. W., \& Boyd, R. L. (2019). Examining longterm trends in politics and culture through language of political leaders and cultural institutions. Proceedings of the National Academy of Sciences of the 
United States of America, 116(14), 7148-7148.

https://doi.org/10.1073/pnas.1811987116

Jost, J. T., Glaser, J., Kruglanski, A. W., \& Sulloway, F. J. (2003). Political conservatism as motivated social cognition. Psychological Bulletin, 129(3), 339-375.

https://doi.org/10.1037/0033-2909.129.3.339

Karvetski, C. W., Meinel, C., Maxwell, D. T., Lu, Y., Mellers, B. A., \& Tetlock, P. E. (in press). What Do Forecasting Rationales Reveal About Thinking Patterns of Top Geopolitical Forecasters? International Journal of Forecasting.

Khalid, A., \& Detrow, S. (2016, October 26). How Trump and Clinton are framing their closing arguments. National Public Radio. http://www.npr.org/2016/10/26/499321154/clinton-and-trump-the-final-sprint

Lauter, D., \& Hook, J. (2020, November 4). Americans broke a 120-year-old turnout record - and are more divided than ever. LA Times. https://www.latimes.com/politics/story/2020-11-04/2020-election-trumpbiden-count-analysis

Lee, B. X. (Ed.). (2017). The dangerous case of Donald Trump: 27 psychiatrists and mental health experts assess a president. Thomas Dunne Books.

Luks, S., \& Elms, L. (2005). African-American partisanship and the legacy of the Civil Rights movement: Generational, regional, and economic influences on democratic identification, 1973-1994. Political Psychology, 26(5), 735-754. https://www.jstor.org/stable/3792310

Lundberg, C., \& Gunn, J. (2017, January 20). Trump's inaugural speech: Is it 
morning or mourning in America? The Conversation.

https://theconversation.com/trumps-inaugural-speech-is-it-morning-ormourning-in-america-71656

Mansoor, S. (2020, February 5). Nancy Pelosi ripped up a copy of Trump's State of the Union Address. Time. https://time.com/5778099/pelosi-trump-speechrip/

Martin, J. (2020, April 21). Biden always had a simple message. He rode it to the nomination. The New York Times. https://www.nytimes.com/2020/o8/21/us/politics/Joe-Biden-Democraticnominee.html

McCammon, S. (2016, November 5). Donald Trump has brought on countless controversies in an unlikely campaign. National Public Radio. https://www.npr.org/2016/11/o5/500782887/donald-trumps-road-to-electionday

McCullough, H. (2019). "Hey! Listen!” Video game dialogue, integrative complexity and the perception of quality. Press Start, 5(1), 94-107. http://press-start.gla.ac.uk

McCullough, H., \& Conway, L. G. III. (2018a). “And the Oscar goes to ...”: Integrative complexity's predictive power in the film industry. Psychology of Aesthetics, Creativity, and the Arts, 12(4), 392-398. https://doi.org/10.1037/acaoooo149

McCullough, H., \& Conway, L. G., III. (2018b). The cognitive complexity of Miss Piggy and Osama Bin Laden: Examining linguistic differences between fiction and reality. Psychology of Popular Media Culture, 7(4), 518-532. http://dx.doi.org/10.1037/ppmoooo150

McCullough, H., \& Conway, L. G., III. (2019, April 20). The integrative complexity of over 
200,000 tweets [Poster presentation]. Rensselaer Polytechnic Institute Graduate Research, Troy, NY, United States. https://doi.org/10.13140/RG.2.2.31847.09121

Mell, J. N., Jang, S., \& Chai, S. (2021). Bridging temporal divides: Temporal brokerage in global teams and its impact on individual performance. Organization Science, 32, 731-751.

Olinger, D. (2016, March 20). Rise of the wordsmiths. Denver Post. https://www.denverpost.com/2008/03/20/rise-of-the-wordsmiths/

Ott, B. L. (2017). The age of Twitter: Donald J. Trump and the politics of debasement. Critical studies in Media Communication, 34(1), 59-68. https://doi.org/10.1080/15295036.2016.1266686

Page, S. (2017, January 20). Analysis: Trump's short, dark and defiant inaugural address. USA Today. https://www.usatoday.com/story/news/politics/2017/01/20/donaldtrump-president-inauguration-speech-analysis-defiant-address-and-politicalrevolt/96836152/

Peters, G. Table of Presidential Inaugural Addresses (University of California, Santa Barbara). The American Presidency Project. https://www.presidency.ucsb.edu/node/324108

Prinsloo, C. F. (2016). Investigating the influence of individual value systems and risk propensities on decision-making quality in value clashing circumstances (Doctoral dissertation, University of Pretoria).

Putra, I. E., Erikha, F., Arimbi, R. S., \& Rufaedah, A. (2018). Increasing integrative complexity on convicted terrorists in Indonesia. Social Psychology and Society, 9(2), 35-45. https://doi.org/10.17759/sps.2018090203 
Repke, M. A., Conway, L. G., III, \& Houck, S. C. (2018). The strategic manipulation of linguistic complexity: A test of two models of lying. Journal of Language and Social Psychology, 37(1), 74-92. https://doi.org/10.1177/0261927X17706943

Roche, C. (2021, January 14). What was the reason why Trump was impeached the first time? AS. https://en.as.com/en/2021/o1/14/latest_news/1610637719_701767.html

Schaller, M., Hofer, M.K., \& Beall, A.T. (2017). Evidence That an Ebola Outbreak Influenced Voting Preferences, Even After Controlling (Mindfully) for Autocorrelation: Reply to Tiokhin and Hruschka (2017). Psychological Science, 28(9), 1361-1363. https://doi.org/10.1177/0956797617718183

Smith, A., Alexander, P., Welker, K., \& Memoli, M. (2020, April 14). Obama endorses Biden for president, says he's the right person to 'guide us through one of our darkest times'. NBC News. https://www.nbcnews.com/politics/2020election/obama-endorse-joe-biden-tuesday-n1183451

Stein, R. (2017). “Trumping” conformity: Urges towards conformity to ingroups and nonconformity to morally opposed outgroups. Journal of Experimental Social Psychology, 70, 34-40. https://doi.org/10.1016/j.jesp.2016.12.007

Suedfeld, P. (1992). Cognitive managers and their critics. Political Psychology, 13(3), 435-453. https://doi.org/10.2307/3791607

Suedfeld, P. (2010). The cognitive processing of politics and politicians: Archival studies of conceptual and integrative complexity. Journal of personality, 78(6), 16691702. https://doi.org/10.1111/j.1467-6494.2010.00666.x 
Suedfeld, P., \& Jhangiani, R. (2009). Cognitive management in an enduring international rivalry: The case of India and Pakistan. Political Psychology, 3o(6), 937-951. https://www.jstor.org/stable/25655431

Suedfeld, P., \& Rank, A. D. (1976). Revolutionary leaders: Long-term success as a function of changes in conceptual complexity. Journal of Personality and Social Psychology, 34(2), 169-178. https://doi.org/10.1037/o022-3514.34.2.169

Suedfeld, P., Tetlock, P. E., \& Ramirez, C. (1977). War, peace, and integrative complexity: UN speeches on the Middle East problem, 1947-1976. Journal of Conflict Resolution, 21(3), 427-442. https://doi.org/10.1177/002200277702100303

Tarrance, V. L. (2017, January 11). The 'divided states of America'? Gallup. https://news.gallup.com/opinion/polling-matters/201728/divided-statesamerica.aspx

Thiessen, M. A. (2020, March 12). It's fair to speculate whether Biden is mentally fit to be president. Washington Post. https://www.washingtonpost.com/opinions/2020/03/12/its-fair-speculatewhether-biden-is-mentally-fit-be-president/

Thoemmes, F. J. \& Conway, L. G., III (2007). Integrative complexity of 41 U.S. presidents. Political Psychology, 28(2), 193-226. https://www.jstor.org/stable/20447033

Tetlock, P. E. (1981). Pre-to postelection shifts in presidential rhetoric: Impression management or cognitive adjustment. Journal of Personality and Social Psychology, 41(2), 207-212. https://doi.org/10.1037/0022-3514.41.2.207 
Tetlock, P. E. (1983). Accountability and complexity of thought. Journal of Personality and Social Psychology, 45(1), 74-83. https://doi.org/10.1037/0022-3514.45.1.74

Tetlock, P.E. (1985). Integrative complexity of American and Soviet foreign policy rhetoric: A time-series analysis. Journal of Personality and Social Psychology, 49(6), 1565-1585. https://doi.org/10.1037/0022-3514.49.6.1565

Wasike, B. (2017). Charismatic rhetoric, integrative complexity and the U.S. Presidency: An analysis of the State of the Union Address (SOTU) from George Washington to Barack Obama. Leadership Quarterly, 28(6), 812-826. https://doi.org/10.1016/j.leaqua.2017.04.002

Winter, D. (1993). Power, affiliation, and war: Three tests of a motivational model. Journal of Personality and Social Psychology, 65(3), 532-545. https://doi.org/10.1037/0022-3514.65.3.532

Winter, D. G. (2007). The role of motivation, responsibility, and integrative complexity in crisis escalation: Comparative studies of war and peace crises. Journal of Personality and Social Psychology, 92(5), 920-937. https://doi.org/10.1037\%2Foo22-3514.92.5.920

Winter, D. G. (2018). What does Trump really want? Analyses of Social Issues and Public Policy, 18(1), 155-171. https://doi.org/10.1111\%2Fasap.12154

Woodard, S. R., Chan, L., \& Conway, L. G. (2021). In search of the cognitively complex person: Is there a meaningful trait component of cognitive complexity? Personality and Social Psychology Review, 25(2), 95-129. https://doi.org/10.1177/1088868320972299

Zubrod, A., Conway, L. G., III, Conway, K. R., \& Ailanjian, D. (2021). Understanding the 
role of linguistic complexity in famous trial outcomes. Journal of Language and Social Psychology, 4O(3), 354-377. https://doi.org/10.1177/0261927X20958439 